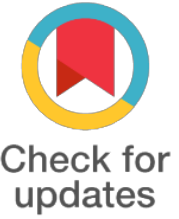

*For correspondence:

Competing interests: The authors declare that no competing interests exist.

Received: 2017-06-17

Accepted: 2017-08-15

Published: 2017-09-05

Copyright The Author(s) 2017. This article is published with open access by BioMedPress (BMP).

This article is distributed under the terms of the Creative Commons Attribution License (CC-BY 4.0) which permits any use, distribution, and reproduction in any medium, provided the original author(s) and the source are credited.

\author{
Nguyen Cong Hoang, Ngo Thi Tinh, Hoang Quoc Cuong \\ Thai Nguyen National General Hospital, Thai Nguyen Medical College, Vietnam
}

ORAL

\title{
Malnutrition and Quality of Life in Patients with Non-Small-Cell Lung Cancer at Thai Nguyen Cancer center
}

Abstract

Nowadays Progressive weight loss, common reduces performance and quality of life in patients with advanced lung cancer. However, there is a paucity of studies that focus on nutritional status and quality of life of non-small cell lung cancer (NSCLC) patients. The present study seeks to determine the nutritional status, and its relation to quality of life, of NSCLC patients. One hundred NSCLC patients (mean age 6o,1 years) were evaluated during therapy at the Lower Silesian Center of Lung Diseases in Thai Nguyen - Vietnam. Nutritional status was evaluated by means of the Mini-Nutritional Assessment (MNA) and quality of life by means of two instruments developed by the European Organization for the Research and Treatment of Cancer (EORTC): QLQ-C 30 and QLQ-LC13 questionnaires. The MNA revealed that up to $49,1 \%$ of patients were undernourished, $24,9 \%$ were at risk of malnutrition, and only $26.0 \%$ showed a normal nutrition. The well-nourished respondents evaluated their quality of life better in all functional scaOLQ-C 30 and specific LC13 questionnaires. In univariate analysis, malnutrition significantly correlated with decreased quality of life and the intensity of symptoms in both questionnaires. In multivariate analysis, malnutrition was an independent determinant of decreased quality of life in physical functioning domain $(\beta 1 / 40.015 ; p<0.001)$. We conclude that malnutrition has an impact on quality of life and on the presentation of symptoms in NSCLC patients. Therefore, nutritional care should be integrated into the global oncology as an adjunct to symptomatic treatment. les (33.3 vs. 41.7 vs. 66.7, respectively) and presented less intensive symptoms in general, research has contributed to the current viewpoint cancer treatment.

\section{Keywords}

Malnutrition, Mini-nutritional assessment • Non-small cell lung cancer

\section{Funding}

\section{References}

